\title{
Implantação de Programas e Redefinição de Práticas Profissionais
}

\author{
Implantation of Programs and Redefinition \\ of Professional Practices
}

Maristela Chitto Sisson

\section{PALAVRAS-CHAVE: \\ - Prática Profissional. \\ - Educação Médica. \\ - Serviços de Integração Docente- Assistencial. \\ - Programa Saúde da Família. \\ - Avaliação de Programas. \\ - Avaliação de Serviços de Saúde.}

\section{KEYWORDS:}

- Professional Practice.

- Medical Education.

- Teaching Care Integration Services.

- Family Health Program.

- Program Evaluation.

- Health Services Research.

Recebido em: 08/11/2007

Reencaminhado em: 28/12/2007

Aprovado em: 27/02/2008

$92 \frac{\text { REVISTA BRASILEIRA DE EDUCAÇ,̃̃o MÉDICA }}{33(1 \text { Supl. 1): 22-103; } 2009}$
Com o objetivo de avaliar as perspectivas de incorporação de novas características ao perfil profissional médico na implantação de novas práticas de atenção (Programa de Saúde da Família) no Programa de Articulação Docente-Assistencial de Florianópolis, entrevistaram-se preceptores e alunos da décima fase do internato médico do curso de Medicina da Universidade Federal de Santa Catarina. A análise indicou que o tipo de desempenho no presente e a socialização representada pela oferta da experiência pela universidade foram fatores explicativos potentes para compreender a incorporação de novas características identitárias pelos alunos e novas variações na identidade dos profissionais. Os estudantes reconheceram a necessidade de adquirir novos perfis de práticas e de saberes para recuperar as bases éticas e relacionais da medicina, consideradas perdidas com a tecnificação e especialização da profissão. Avaliaram o PSF como mercado de trabalho promissor e uma possibilidade intermediária até o alcance da situação ideal na posição especializada.

\section{ABSTRACT}

The principal factors that influence and configure professional insertion in societies with regulated labor markets and complex, well-structured healthcare systems and professional organizations are the assistance modalities, the professional competences and the technological organization of labor. To evaluate the perspectives for the incorporation of new characteristics to the medical professional profile while implanting new service practices (Family Health Program) in the context of the Program for Articulation of Teaching and Service in Florianópolis, we interviewed teachers and fifth year medical students at the Federal University at Santa Catarina. The results revealed that the current performance in healthcare practices and the socialization offered by the university experience are factors contributing strongly to understanding the incorporation of new identity characteristics by students and professionals. The students recognized the need to acquire new practices and knowledge profiles and to restore the ethical bases and relationships of medicine that were lost with specialization and the extremely technical character of modern medicine. Nevertheless, a desire for specialization still remains among the students, who consider the Family Health Care Program as a promising labor market until they achieve an ideal professional specialization. 


\section{INTRODUÇÃO}

Na dimensão das políticas de saúde, as políticas de Recursos Humanos (RH) têm destaque especial, por serem detentoras de uma problemática que influencia e constrange os modelos de atenção à saúde, repercutindo não somente na formação e capacitação dos profissionais, mas também em sua inserção nos serviços de saúde. No que diz respeito à produção/oferta de serviços de saúde, têm implicações de fundamental importância para o SUS, por deterem instrumentos e meios para a adequada preparação e gestão dos RH destinados à sua operação.

É recente o reconhecimento da necessidade de mudanças nos processos de trabalho, na gestão e na formação dos profissionais da área da saúde, assim como no sistema de ensino, principalmente nas universidades, onde existe grande resistência e dificuldade de mudanças e onde continuam sendo formados profissionais preparados para atuar em modelos assistenciais que algumas reformas de sistemas e serviços de saúde buscaram superar.

Esta ampliação do campo de desenvolvimento de recursos humanos vem se dando por meio da concepção de RH como sujeito social, situado historicamente no interior de complexas estruturas sanitárias e sociais. Portanto, os profissionais que realizam intermediações nos modos e na organização dos processos de produção e de prestação dos serviços de saúde estão entre os que mais podem tornar possíveis as transformações necessárias à melhoria de saúde da população.

De outro lado, o serviço de saúde, como natural e maior empregador desse contingente, tem importante papel na determinação das necessidades de profissionais competentes. Em função das exigências de novos modelos de atenção à saúde - como, por exemplo, no caso do Brasil, o Programa de Saúde da Família, PSF $^{1,2}$-, que demandam um processo de reorganização e reorientação dos serviços, são escassos no mercado de trabalho profissionais com um perfil de formação correspondente. É preciso desenvolver projetos educacionais que dêem conta dos problemas do cotidiano do exercício profissional, que não podem ficar a cargo exclusivo do Sistema de Saúde, mas devem ser compartilhados pelas escolas e universidades ${ }^{3}$.

Como a categoria médica continua hegemônica na equipe de saúde e mantém seu papel de destaque nas ações de saúde, considera-se que ela é indispensável à mudança do setor, embora seja a que apresenta maior resistência ${ }^{4}$.

No início do século XX, duas propostas diagnósticas e de reformulação do ensino médico influenciaram fortemente o ensino na área e mesmo no interior dos sistemas de saúde: o informe de Abrahan Flexner, em 1910, que influenciou as faculdades dos Estados Unidos, do Canadá e posteriormente da América Latina; e o informe de Bertrand Dowson, em 1920, com influência sobre as faculdades da União Soviética e da Inglaterra durante a Segunda Guerra Mundial, e a definição do Plano Beveridge ${ }^{5}$, que mais tarde fundaria o Sistema Nacional de Saúde do Reino Unido.

É possível considerar que o modelo flexneriano constituiu uma forte influência na conformação dos cursos médicos nas universidades norte-americanas por 40 anos, bem como nas faculdades da América Latina e do Brasil a partir das décadas de 1940 e 50.

Nos anos 1970, surge na América Latina a estratégia de Integração Docente-Assistencial (IDA) ${ }^{5-8}$, para superação das experiências de demonstração dirigidas a pequenos grupos populacionais levadas a cabo pelos departamentos de medicina preventiva e denominadas "laboratórios de comunidade". Essa proposta alternativa visava à inter-relação entre todos os setores da escola médica e parcela significativa dos serviços de saúde, num contexto regionalizado, com todos os níveis da atenção.

A temática sobre a IDA e as relações entre instituições educativas e de serviços foi reiteradamente discutida nos anos 1970 e 80, constituindo uma das tendências da área de formação de RH na América Latina. Ela foi levada em conta como critério essencial no planejamento de muitas mudanças educacionais, tendo apresentado enormes variações: desde a simples utilização dos serviços como espaços de prática, até tentativas de reorganização do processo educativo ao redor de um novo modelo de organização de serviços?.

No Brasil, no processo de discussão para a constituição do SUS, as várias propostas, projetos, planos e programas nem sempre incluíam a questão dos recursos humanos necessários para o sistema funcionar a contento. A tendência reformadora que se manifestava na área de recursos humanos apontava a necessidade de integrar os dois sistemas - utilizador e formador de recursos humanos ${ }^{5}$. Isto para reverter as dificuldades criadas pelo uso de um referencial de determinação de necessidades de saúde de cunho biologicista, que, após os anos 1950, foi assumido pela Academia e profissionais da saúde como produção do conhecimento sobre doenças. Além disso, apontava-se que a excessiva especialização acarretava uma falta de conhecimento técnico geral ao perfil profissional ${ }^{10}$.

Para superar estas dificuldades, emergiram na década de 1980 as propostas de Integração Docente-Assistencial no Brasil (IDA), marcadas pelo contexto de reestruturação do padrão de proteção social, que buscava reformular o sistema de saúde com base nos princípios da universalização dos direitos, descentralização das decisões, unificação dos serviços, eqüidade na prestação dos benefícios e controle social sobre o sistema. 
O modelo proposto não defendia a existência de serviços próprios das universidades ou serviços de extensão universitária, mas previa a integração da universidade com os serviços de saúde existentes. Essa integração deveria se dar por meio de uma interação permanente e não mediante o uso eventual dos serviços pela universidade. A interação deveria promover vivências práticas dos alunos na realidade concreta e a participação deles no currículo e conteúdo acadêmicos. Esperava-se que este processo levasse a alterações profundas nos currículos das faculdades da área da saúde, nas práticas e nas relações aluno-professor.

No País, várias experiências localizadas se desenvolveram, integrando estas tendências. O município de Florianópolis implementou uma experiência nestes moldes, que mais tarde iria constituir uma referência para a implantação do Programa de Saúde da Família (PSF).

O PSF é a mais recente proposta do Ministério da Saúde de modelo de atenção para o Sistema Único de Saúde brasileiro. Os documentos ministeriais o referenciam com grande ênfase político-ideológica ao conferirem à humanização da assistência e ao vínculo de compromisso e co-responsabilidade entre serviços e população a responsabilidade de tornar o programa um projeto de grande potencial transformador.

Os resultados esperados do programa são transformações significativas no modelo de atenção, capazes de reverter o modelo assistencial vigente pela mudança do objeto de trabalho e pela forma de atuação e organização geral dos serviços. A partir da atenção básica, propõe a reorganização da prática assistencial em substituição ao modelo tradicional de assistência, orientado para a cura de doenças e realizado principalmente no hospital ${ }^{11}$. Suas características principais são adscrição da clientela por equipe com base territorial, cadastramento da população, trabalho inter e multidisciplinar com equipe mínima, ter a família como objeto do cuidado.

Apontada como grande desafio para a consecução das metas, a questão dos recursos humanos adequados para operacionalizar o programa assume caráter estratégico.

A Constituição Federal de $1988^{11}$ define a competência do SUS para ordenar a formação de recursos humanos na área da saúde, dando o amparo legal necessário para que "os serviços" exijam uma adequação do ensino. Em novembro de 1990, ocorre a regulamentação do SUS por intermédio da Lei 8.08012, que define esta ordenação como objetivo e atribuição do SUS.

O processo começou a ser debatido com a realização das Conferências Nacionais de Recursos Humanos, que avançaram na discussão, contemplando as quatro áreas de consolidação da política de RH apontadas como fundamentais a seu desenvolvimento: mercado de trabalho, educação e treinamento, gerenciamento e condições de trabalho ${ }^{13}$, não implementadas até hoje, em sua grande maioria ${ }^{14}$.

Nos últimos anos, as questões de formação de RH têm encontrado espaço na agenda política do setor. No campo da Medicina, destaca-se o desenvolvimento de um programa nacional de incentivo às mudanças curriculares, que contou com o apoio da maior parte das escolas médicas do País ${ }^{15}$.

Houve um avanço considerável na direção de que as bases das mudanças necessárias deveriam passar do domínio de políticas voltadas à gestão de $\mathrm{RH}$ - moldadas pela visão de que o mercado de trabalho exclusivamente condiciona e determina as características do aparelho formador, em particular da Medicina - para uma visão que considera as várias interfaces entre mercado de trabalho ou prática profissional e estrutura acadêmico-administrativa dos cursos ou prática educativa.

\section{PROFISSÃO MÉDICA, FORMAÇÃO MÉDICA E IDENTIDADE PROFISSIONAL}

Os modelos de atenção à saúde, as competências profissionais e a organização tecnológica do trabalho implantados em diferentes sistemas de diversos países são fatores determinantes da inserção profissional nas sociedades contemporâneas e são influenciados e influenciam a organização das corporações profissionais. Nesse sentido, novos modelos de saúde que demandam novas propostas de práticas exigem "novos profissionais", ou novas construções identitárias, como é o caso dos profissionais necessários à operacionalização do PSF.

Existe, atualmente, um processo de recomposição de identidades profissionais, categorias estas que também não são adquiridas para sempre, pois se elaboram a partir de uma trajetória pessoal que desborda os limites do trabalho ${ }^{16}$.

Vários autores ${ }^{16-19}$ concordam em apontar ampliações na explicação sociológica das profissões e das identidades profissionais, ampliando a análise para além de seus determinantes macrossociais e incorporando a dimensão da participação humana na formação e transformação das relações e instituições sociais. As sociedades modernas produzem múltiplos centros, onde novas identidades podem emergir, novos sujeitos podem se expressar, e mudanças na natureza da prática profissional podem influenciar na construção destas identidades. A forma pela qual os profissionais constroem essas identidades e se inserem em novas propostas de práticas envolvem dimensões relativas à sua organização profissional.

A profissão médica tem o atributo de ser dominante e é avaliada por vários autores como protótipo do profissionalis$\mathrm{mo}^{20}$.

O domínio da profissão médica representa uma combinação entre conhecimento e poder, e se baseia nas características 
de status e poder profissionais concedidos ao médico. A estes se agregam as habilidades para o uso do que se denomina "liberdade clínica" ${ }^{21}$. Este poder é garantido pela autonomia e conhecimento ou saber profissionais, e o domínio se dá claramente pela apropriação de um corpo de conhecimentos, aspecto fundamental do exercício do poder profissional, que permite suficiente escopo para interpretação do resultado, em relação ao qual o paciente ou cliente permanece relativamente ignorante e subordinado.

O conceito de prática como uso do saber é subordinado a um contexto constituído pela estrutura de produção e por uma relação entre indivíduos. Desta forma, o uso do conhecimento ou do saber esotérico significa a prática do saber realizada por um agente que possui alguma possibilidade de intervenção sobre determinados contextos. Estes atributos influenciam a organização de serviços de saúde e suas práticas ${ }^{21}$.

O profissionalismo e a autonomia médica fazem parte dos principais temas das agendas dos países europeus com processos de mudança na formação profissional. Na América Latina, entretanto, há grande riqueza na discussão e inúmeras prescrições a respeito do que políticas de reforma devem introduzir no campo de formação de $\mathrm{RH}$, mas poucos encaminhamentos práticos e efetivos foram possíveis.

A profissão médica, como as profissões em geral, além da regulamentação profissional, está submetida à regulamentação institucional, considerado um aspecto muito influente em sua constituição ${ }^{22}$. O estudo das instituições burocráticas revela que, quanto mais fraca for a definição das regras institucionais, mais forte será a influência de concepções singulares de cada profissional em suas práticas. Experiência, profissionalismo e ideologia parecem ter maior influência quando as leis, regras e circunstâncias da organização não definem precisamente a tarefa do operador. Sendo assim, quem define em grande medida o comportamento profissional são as normas organizacionais ${ }^{23}$.

Entre as questões que definem a identidade profissional, a formação profissional tem papel preponderante, que vai além da incorporação das bases técnicas da prática. Além de aspectos subjetivos referentes ao processo de interação com o cliente, inclui idéias, valores e padrões adquiridos e compartilhados com a corporação a que pertencem e que orientarão sua atuação profissional futura ${ }^{24}$.

Os estudos de Garcia ${ }^{25}$ confirmam as concepções que valorizam a estrutura das relações que surgem no processo de ensino como fundamento de toda transformação educacional profunda. Embora se reconheçam as influências que as características da escola possam ter sobre o processo de produção de médicos, a maneira de formá-los orienta a ordem institucio- nal. E mudanças neste modo de formação podem desenvolver transformações efetivas nos moldes de organização da prática médica. O processo de produção de médicos, por sua vez, não é isolado, encontrando-se ainda estreitamente relacionado à estrutura econômica predominante na sociedade, entre outras interações.

No transcorrer do processo de ensino médico, a socialização de adultos ultrapassa os limites da educação e do treinamento e se desenvolve mediante duas formas principais: o aprendizado direto, por meio do ensino didático, e o aprendizado indireto, em que o contato com instrutores e colegas, com pacientes e com membros da equipe de saúde gera padrões de comportamento, atitudes e valores que serão incorporados, fazendo da escola médica uma organização social que pode transmitir a forma mais duradoura de aprendizado ${ }^{26}$ Sendo assim, a apreensão do cenário onde vão ser realizadas as práticas assistenciais e a busca de uma identificação com o professor são fatores que determinam a aquisição de conteúdos e habilidades técnicas. É principalmente nas atividades realizadas em ambulatórios e enfermarias que o aluno vai construindo sua identidade profissional e adquirindo os valores sociais de uma prática com implicações pelo modo de ser vivenciada e realizada.

Estes alunos, em sua condição de quase médicos, realizam a experiência prática de forma intensa. Mas sua concepção da medicina permanece predominantemente como uma prática de sentido único. Esta prática significa uma oportunidade de exercitar um saber/poder que cura, reduz ou controla as doenças, mediante ações cuja eficácia depende do grau de desenvolvimento alcançado pelo conhecimento técnico. O sonho do domínio total de pelo menos um campo do conhecimento é buscado por meio da especialização médica, que, além disso, se dirige para a fragmentação da prática médica, que afasta o entendimento no que concerne à mediação da relação entre os sujeitos sociais que participam do ato médico e se reduz a uma intervenção imediata sobre um pedaço de $\operatorname{corpo}^{27}$.

Na tentativa de superar estas dificuldades e buscar um perfil mais geral para o médico, há cursos que oferecem experiências de ensino articuladas aos serviços públicos de saúde, nos moldes da Integração Docente-Assistencial. Há que se evitar, porém, o deslocamento de estudantes até os centros de saúde ou a comunidade com uma programação construída unilateralmente pelo professor. Isto é muito diferente de uma integração baseada num plano conjunto, que leva em conta interesses dos serviços de saúde e da comunidade, e não apenas os de ensino-aprendizagem ${ }^{28}$.

A participação do bairro ou da comunidade envolvidos na definição das atividades a serem realizadas provoca subs- 
tanciais modificações na forma de pensar as ações de saúde, ao contrário da forma na qual é a população que deve se adaptar totalmente ao que é oferecido.

Além dos aspectos de construção de identidade durante a formação médica, alguns autores ${ }^{20,29}$ afirmam que o tipo de desempenho na prática profissional cotidiana constitui um fator mais influente do que a socialização anterior na faculdade. E que as situações vividas no momento presente de realização das práticas profissionais têm um peso maior do que o passado internalizado para a compreensão das principais variações no desempenho profissional.

Isto quer dizer que a socialização profissional efetiva de uma categoria profissional, relativa a modos de pensar e de atuar, individual ou coletivamente, completa-se e se consolida no âmbito da prática profissional. As formas de relação social (hegemonia, processo decisório, conflito, controle do saber) e as práticas técnicas (divisão do trabalho, circuitos operativos, saber fazer) são construídas historicamente e funcionam como matriz de aprendizagem nos locais de trabalho, inclusive com uma importância maior do que a identidade profissional adquirida no processo escolar formal. A partir daí, é destacada não a inutilidade dos cursos de graduação, mas, sim, que as práticas sanitárias podem tanto dificultar como facilitar as aprendizagens transformadoras ${ }^{29}$.

Tomando o comportamento profissional como produto da identidade profissional construída, seria possível, por meio das mudanças de modelo orientadas por normas organizacionais, influenciar as identidades profissionais?

Com o propósito de contribuir para discutir essa questão, desenvolveu-se esta pesquisa, parte de um estudo maior ${ }^{30}$. Seu objetivo foi avaliar as perspectivas de incorporação de novas práticas e de novas características ao perfil profissional de médicos preceptores e alunos do internato médico do curso de Medicina da Universidade Federal de Santa Catarina (UFSC) na implantação de novas práticas de atenção (Programa de Saúde da Família) no Programa de Articulação Docente-Assistencial de Florianópolis (PDA).

\section{METODOLOGIA}

As avaliações de programa, de maneira geral, dizem respeito a inúmeros objetos e diversos contextos, mas surgem com maior freqüência ligadas a temas políticos e sociais, e estão relacionadas, de forma preponderante, a ações que ocorrem em nível de governo ${ }^{31}$. O que distingue fundamentalmente uma metodologia de avaliação da outra não são os métodos, mas as questões que são indexadas e os valores promovidos ${ }^{31}$.

Em função das questões avaliativas em estudo, foi desenvolvida uma abordagem qualitativa de investigação, de natu- reza situacional ${ }^{32-35}$, constituindo um estudo de caso $^{36}$ do tipo observacional $^{37}$, recurso utilizado para aumentar a profundidade da avaliação e que permite comparações dentro de um grupo para explicar características únicas de seus membros. Foi realizada em um contexto natural, por meio de entrevistas com roteiros semi-estruturados, aplicadas sobre indivíduos e sobre análise de documentos.

Como forma de apreensão do objeto de investigação, foram priorizadas as visões de profissionais médicos/preceptores e alunos da décima fase do internato médico do curso de Medicina da UFSC em estágio no Programa de Articulação Docente-Assistencial. As entrevistas foram realizadas antes e seis meses após a implantação, período em que se realizava a transição para o modelo do Programa de Saúde da Família, captando, nos entrevistados, momentos de máxima expectativa em relação ao programa.

A partir de uma primeira análise que identificou consensos temáticos específicos entre estes participantes, buscou-se captar a visão dos entrevistados sobre os programas, as possíveis mudanças instituídas pelo PSF e a capacidade deste em intermediar novos processos tecnológicos para a atenção à saúde.

\section{Contexto local}

Em 1997, o município de Florianópolis implementou uma experiência nos moldes da Integração Ensino-Serviços, denominada Programa de Articulação Docente-Assistencial de Florianópolis ${ }^{38}$, que posteriormente se configurou como base referencial para a implantação do Programa de Saúde da Família na rede municipal de saúde. O programa se iniciou dirigido ao recém-criado internato médico da décima fase curricular do curso de Medicina, agregando-se, depois, disciplinas dos cursos de Enfermagem, Nutrição, Farmácia, Serviço Social e Psicologia.

O principal efeito esperado do Programa Docente-Assistencial era a formação de profissionais aptos a trabalhar na promoção da saúde e na resolução de problemas do nível primário de atenção, de acordo com as diretrizes do SUS. Pesquisa na área e multiplicação de experiências práticas para a rede de saúde também eram resultados desejados. A partir de 2003, com o novo Projeto Curricular Integrado do Curso de Medicina, o programa se ampliou e constitui um dos cenários-eixo para todo o curso de Medicina.

\section{Visões dos Médicos Preceptores e Alunos}

Buscou-se conhecer as percepções dos atores dos programas em relação ao cenário de implantação e aos constituintes da nova proposta enquanto uma prática em construção, por 
meio de mudanças na conformação de suas identidades e de suas práticas profissionais, e da organização de novos processos tecnológicos propostos pelo programa.

A condução e o desenvolvimento desse processo foram ocupados por sujeitos sociais, que formavam uma "comunidade de práticas" representada pela participação no PDA. O grupo continha processos subjetivos e intersubjetivos, e uma contínua reconstrução de identidades, assim como projetos coletivos, que encontraram suas possibilidades de produção e exercício e, igualmente, suas limitações.

Tudo se relaciona, o Docente-Assistencial é o modelo do PSF, nós do PDA fazemos o PSF desde a sua origem, as mesmas práticas, preparamos os recursos humanos pra isso. A diferença principal é que tem ensino e algumas pesquisas, essa é que é a diferença, que se trabalha com o ensino dos acadêmicos das diversas áreas. (M1)

Não foi uma coisa determinada assim, eu vou ser isso. Aconteceu na minha vida. E depois daí, sempre permaneci neste tipo de trabalho.(M2)

Muita coisa do programa eu acho que já fazia, porque antes de voltar para Florianópolis, no interior, eu já tinha essa idéia, já tinha conseguido formar uma equipe no município onde eu trabalhava. (M4)

Na conformação e designação destes sujeitos, emergiram as questões de identidade profissional, do sujeito profissional vinculado às tecnologias de trabalho, às questões do ensino e à interação nas práticas cotidianas. Todas elas reforçaram a importância dos cenários adequados à formação da identidade médica, tanto durante o processo de socialização vivenciado na graduação, como naqueles efeitos sentidos em função dos processos de mudança nas identidades profissionais dos já médicos, experimentados na implantação de novos modelos assistenciais, como foi, no caso, o PSF, demonstrando que a experiência de integração ensino-serviços promove grande aproximação do perfil profissional necessário ao PSF.

O que eu acho mais interessante é você realmente andar pelo bairro, percorrer, poder ver as pessoas, conversar com as pessoas, porque isso aí te dá mais segurança e tranqüilidade [...] Eu acho que há um vínculo forte. É a certeza que você tem no profissional e que aquele profissional vai estar presente. $\mathrm{O}$ aluno vivencia isso[...] (M3)

Antes eu trabalhava como médico geral num posto onde apareciam, por exemplo, muitas DSTs, mas não conhecia o processo inteiro, encaminhava o paciente [...] Eu tive que retomar [...] Foi superin- teressante, fez com que eu desse uma reciclada em toda essa parte da atenção primária, inclusive para trabalhar com os alunos. (M5)

Tu sais de uma prática assistencial individualizada que tu estás realizando, para uma prática que é muito mais coletiva. É uma prática que vê as famílias, que vê a própria comunidade. Então, você passa a ver o teu trabalho não como um trabalho único e indispensável, você passa a ver o teu trabalho como um trabalho a mais dentro de uma equipe e não é você que tem que dar a resposta. De certa forma, é o trabalho desenvolvido pela equipe e não só pela equipe, mas também com a própria comunidade, e de muitas maneiras, e que melhora o acesso. (M3)

Com os alunos, tem que estar pronto para discutir tudo, para que eles também aprendam, que é o objetivo maior, e também a participação, o médico participa de todas as atividades ou da maioria delas junto com a equipe, com as enfermeiras. (M4, M3)

Aqui a gente faz consulta, fica em maior contato com a comunidade, trata os problemas pessoais da família, faz visita na comunidade, tem o pronto atendimento. Agora, a gente fica mais em contato com a família, com a comunidade, é mais pessoal. No hospital, você trata os problemas do paciente, dá um remédio e manda embora, não se preocupa com o depois. (A1)

Na visão dos alunos, por um lado, houve maior compreensão das necessidades de saúde da população e uma ampliação do objeto de trabalho e das práticas, com o reconhecimento de uma atenção coletiva agregada à individual e de uma atenção preventiva agregada à curativa, realizadas mediante práticas interativas, que possibilitavam recuperar a base das relações entre médicos e pacientes, e entre profissionais. Por outro lado, o desenvolvimento desta prática de trabalho pelos alunos se mostrou revestida de um caráter funcionalista, ao ser valorizada pelos estudantes por proporcionar maior efetividade educacional, mas ainda dentro do marco do modelo médico tradicional, respondendo, assim, mais a requerimentos de qualificação profissional.

Tem mais o enfoque da prevenção, pelo que eu percebo. A gente trabalha com prevenção, atende muita criança e vai acompanhando o desenvolvimento dela, não espera chegar com a doença pra ver. A gente acompanha a evolução dela e da gestante também. É o atendimento básico que as pessoas precisam, e sem isso o nosso curso não fica completo. (A4) 
É como se fosse uma outra medicina, porque a gente aprende tradicionalmente, por exemplo, a pegar um paciente que tem esofagite e o resto a gente não querer saber. Este não, procura ver a pessoa integralmente. E ainda há visitas à comunidade, para ver qual é o problema realmente da pessoa, tudo o que influencia. Acho que é interessante pra gente, na nossa formação. (A7)

Eu não olho esse programa como se fosse algo revolucionário: é outra oportunidade para você somar conhecimento no teu período de formação. É uma visão interessante porque ele visa à medicina generalista, algo em que às vezes, durante a formação, você fica muito especialista. Então, esse resgate do médico geral é muito interessante. Mas eu o classifico como um outro bom estágio. (A5)

Na visão dos profissionais, a combinação de múltiplas faces identitárias, entre outros fatores, propiciada pela estratégia de compartilhamento do trabalho articulado ensino-serviços, foi percebida como formadora do perfil do médico-supervisor-preceptor do PDA, aproximando-se do perfil de professores-integradores, de caráter humanista, necessários ao trabalho multiprofissional e interdisciplinar e ao ensino integrado da clínica e da epidemiologia.

É uma possibilidade diferente de trabalhar dentro da medicina, uma medicina que possa não só abordar o indivíduo, mas ter uma abordagem no seu meio, na família, na sua comunidade, perceber o que está ao seu lado e repassar isso ao aluno. (M3)

Para mim este é o grande ganho do aluno, uma atividade diferente da que ele fazia no hospital, onde ele somente descobre casos raros. Esse tipo de vivência dá oportunidade de conhecer a comunidade, o lar das pessoas e o indivíduo que ele atende. (M2)

[...] é repassar esse conhecimento para os acadêmicos, de um atendimento humanizado, com conhecimento epidemiológico do que há na região. (M6)

Há duas vertentes de interpretação desta aproximação da universidade da "realidade" dos serviços no interior do PDA. Na vertente dos alunos, essa aproximação da realidade ocorre em função das necessidades de aprendizagem, diminuindo a distância entre o estudante e a população, e a artificialidade que o ensino provoca, melhorando os resultados da técnica. Nesta vertente, a universidade, por intermédio do PDA, busca aumentar a efetividade no ensino, aproximando-se, assim, da vertente da Atenção Primária de Saúde, mais próxima de uma hierarquização da técnica referenciada pelo conhecimento, na qual a marca da tecnologia baseada nas ciências é mais forte. $\mathrm{Na}$ outra vertente, representada pelos profissionais médicos, a universidade, por meio do PDA, atua para transformar a "realidade" na direção da sociedade, e aqui se aproxima mais dos referenciais da medicina comunitária, colocando o "mundo da vida", as relações interpessoais, como valores que antecedem a técnica.

O estágio é bom para que o estudante tenha uma noção de atendimento primário à população e que tenha uma noção em relação à vida do indivíduo na sociedade e sobre o processo de doença, e que ele tenha estrutura para começar um programa como esse numa outra cidade ou mesmo aqui em um outro posto de saúde. (A3)

[...] tem que entender a dinâmica social do indivíduo e não só o problema individual. (M5)

O programa prevê que se faça um diagnóstico e que, para a maioria desses problemas, haja uma solução político-social e não a solução médica. (M1)

O encontro da técnica com o humano, de forma integrada, no ato médico foi uma preocupação que surgiu reforçada nos supervisores, na tentativa de passar aos alunos a dimensão ética do trabalho em sociedade, que realiza valores ao desenvolver intervenções - como o diagnóstico e a terapêutica - assentadas no manejo direto interpessoal e baseadas em decisões que podem levar a efeitos físicos e também sobre o modo de viver das pessoas. Para os profissionais, estas práticas e saberes seriam essenciais para recuperar a base ética da medicina. Recuperar os indivíduos como pessoas e sujeitos nas práticas e exercitar o saber como reflexão crítica foram consideradas formas de inserção necessárias à experiência da assistência e da docência, e se manifestaram intensamente nos depoimentos.

Primeiro, o médico do PDA tem que estar sempre atualizado, e segundo, é o que conversar com os alunos. Eu sempre digo que a gente não ajuda a fazer diagnóstico, a gente dá lições de vida pros alunos... (M1)

[...] representa uma medicina que busca não só a cura de doenças, mas também prevenir de várias maneiras. Através da conscientização da população da comunidade que o posto atende. [...] ver mais ou menos o estilo de vida que a pessoa está levando, de acordo com a doença que ela tenha ou não, e tentar, dentro do possível, adaptar de uma forma melhor para ela. E tornar mais acessível o serviço de saúde à população. (A2) 
O programa subentende um perfil profissional, treina as pessoas para o exercício da cidadania, a entender o processo de saúde e doença. Ele vai além do diagnóstico médico, ele prevê que se faça um diagnóstico de comunidade e que as pessoas reflitam sobre esse processo de saúde e doença. Isso é bom, isso é um programa de resgate da cidadania. (M1)

É um programa ideal para se passar aos alunos, para que haja mudança de mentalidade dos estudantes. Eu acredito que a formação do médico generalista é através do PSF, que se possa resgatar o trabalho com os cidadãos de uma forma cidadã. (M4)

Permeando a maioria das falas sobre os diferentes aspectos que compunham a identidade profissional e as novas práticas dos profissionais, colocou-se o campo das interações - relacionamento e trabalho com a equipe, criação de vínculos com a população e pacientes, realização de grupos de trabalho, etc. Os processos interativos da prática profissional promovidos pelo Programa de Saúde da Família foram percebidos como tecnologia fundamental de exercício de práticas e como determinantes de mudanças nas identidades profissionais. Os vínculos com a população - que, na visão dos participantes do estudo, se basearam na interação com a comunidade - foram estabelecidos principalmente por meio de uma nova prática, a territorialização, com destaque para o trabalho articulado aos espaços-territórios, as microáreas. Nestas se desenvolvem as relações, incentivando os profissionais a se deslocarem da unidade de saúde até o lugar onde as pessoas moram e trabalham, tornando as práticas "experiências vivas", que demonstram as possibilidades de estreitar as relações com a comunidade. Os estudantes identificaram o "aprender a se relacionar", a estratégia de entender o ponto de vista do outro, de reconhecer o outro como sujeito nas práticas.

O que eu acho mais interessante é você realmente andar pelo bairro, percorrer, poder ver as pessoas, conversar com as pessoas, porque isso te dá mais segurança e tranqüilidade. O médico não é aquele que fica perguntando tudo pro paciente dentro do consultório numa consulta, porque, muitas vezes, ele saindo e indo fazer uma visita domiciliar vê muito mais do que se fizer dez consultas dentro do consultório [...] ele vai poder interagir com a família e isso é que é interessante. [...] Eu acho que há um vínculo forte. Eu acho que é a certeza que você tem no profissional e que aquele profissional vai estar presente [...] porque o grande problema é sempre a rotatividade dos profissionais. Então, quando se tem uma equipe, um profissional que fica no local, isso é uma certeza que as pessoas têm de que vão encontrar aquela pessoa. É o ponto de apoio. Isso foi o que de certa forma facilitou. Em função disso, da equipe do PSF com os alunos do PDA, a população aceitou e gosta dos alunos, quer dizer, o trabalho desenvolvido por eles não é um trabalho que outros médicos façam normalmente, tradicionalmente não fazem, então eu acho que isso colaborou para que as pessoas se vinculassem, alunos também e comunidade. (M3)

[...]na minha experiência de ser médico de família, que é mais viva... Ela é viva, porque lá eu conheço praticamente todas as pessoas da comunidade, são mil pessoas. Conheço todos os jardins, eu sei onde tem a planta que eu preciso... Então, eu era o médico da comunidade mesmo, médico de família, as pessoas me chamavam[...] (M6)

Considero que uma boa prática está em educar a comunidade para que tenha saúde. O PSF propicia esta prática através da educação para saúde do trabalho de grupo, do atendimento à família como um todo, das pessoas integradas à família. Então, não é somente o especialista, médico ou alguém da equipe atendendo a pessoa por um problema específico, mas alguém integrado à sua realidade. (M4)

Na visão dos profissionais e alunos, estas subjetividades permitiriam conformar identidades profissionais, diferentes das que hoje existem.

O trabalho desenvolvido pelos alunos não é um trabalho que outros médicos façam normalmente, tradicionalmente não fazem. (M3)

Se eu fosse capacitar um estudante para trabalhar com atenção primária, PSF... Bom, tem que orientar primeiro para ter uma relação boa com os pacientes. É o principal. O importante é se relacionar bem com as pessoas, saber ouvir o que as pessoas têm para te dizer, conversar, porque elas procuram isso. Além do conhecimento técnico que é necessário, mas principalmente, ouvir, conversar, perguntar[...] (A7)

Ao final da experiência de formação, a maioria dos alunos entrevistados teve uma percepção positiva, falou de um objeto de trabalho ampliado e integral. O aperfeiçoamento da prática clínica, do qual a experiência é um componente, estava representado fortemente nas falas. A partir daí, sugeriram a introdução mais precoce deste tipo de vivência, a ampliação 
de conteúdos e sua melhor sistematização, e um reforço do enfoque preventivo no ensino da atenção em saúde.

Na maioria das vezes, nos hospitais universitários, a gente passa pelo estágio, por aquelas grandes áreas, mas só praticamente pronto atendimento. A pessoa chega doente, mas não com aquela visão de prevenir doenças, fazer o acompanhamento mais a longo prazo do paciente. [...] para a gente, muitas coisas foram importantes. A primeira foi unificar as clínicas, foi a primeira vez que a gente conseguiu unificar as cinco grandes áreas - cirurgia, clínica, pediatria, gineco, saúde pública. Foi a primeira vez que a gente conseguiu unir as cinco no mesmo lugar, de uma mesma maneira, lidando com o público. Deveria ser até um ano de experiência ou começar mais cedo na faculdade, porque dá uma visão maior da medicina. (A3)

Minha opinião e a de muitos colegas, que eu vejo que vale a pena, é que a gente tivesse a oportunidade de ver isso mais cedo. Eu tive a felicidade de fazer estágio com o doutor [...], que foi muito jóia. E eu queria que os meus colegas tivessem essa oportunidade mais cedo também, de vivenciar, de interagir, de juntar tudo. Se está vendo pediatria, mas se está vendo também pneumo naquela criança, e dermato, tudo junto, aí você tem que botar a cabeça pra funcionar. No começo você se assusta, mas depois se surpreende com o que acaba aprendendo. (A1)

Os problemas de saúde são principalmente problemas da água: essa parte de água e esgoto lá é muito difícil. A gente tem muito problema de diarréia por causa de água. E muito alcoolismo. Com o PSF, não sei se esses problemas foram resolvidos. Talvez nesse curto espaço de tempo, não. A curto prazo, não, mas talvez a longo prazo seja o modelo melhor para resolver. A gente começou a conversar mais, pelo menos entre a gente, que não conhecia como era antes, a gente começou a tentar fazer algo e reparou muito nesse problema do alcoolismo e da água. A gente chegou a comentar: "nossa, como é que ninguém vai na prefeitura, alguém na comunidade para reclamar", mas acho que a gente acabou não fazendo... (A6)

Muitos no começo não gostavam do postinho, não queriam de jeito nenhum, agora já estão começando a ver que é fundamental essa formação. Muitos de nós entramos pensando que vamos sair cirurgiões vasculares ou oncologistas, todo mundo já estava definido. O que está mudando é que eles estão começando a perceber a importância de um conhecimento mais abrangente, mais generalista mesmo. (A4)

O desejo de especialização entre os alunos não se modificou, mas estes mostraram estar conscientes da ampliação do mercado de trabalho, representada pela oferta do PSF no setor público:

Eu acredito que o PSF vai ajudar bastante no meu futuro. Eu vou me formar em agosto e pretendo trabalhar até a minha prova de residência, no outro agosto. E vou precisar e o que eu vejo agora que está tendo muita oportunidade é o PSF. Eu não sou "o" experiente, mas tenho uma noção e poderia trabalhar numa prefeitura. (A1)

Tenho certeza de que também vai ser útil pra mim, porque eu não vou terminar a residência depois de dois anos e montar um consultório lindo. Eu vou ter que começar a trabalhar pesado e pôr em prática as coisas que aprendi no PSF. (A5)

Vou fazer residência em ortopedia ou cirurgia. Acho importante todo esse negócio, mas não é o que eu quero pra mim. Eu prefiro ter a vida na cidade, digamos assim. Acho que foi proveitoso para o internato, apesar de todos os problemas que a gente teve. Acho que essa noção de atenção primária é uma coisa muito importante. (A7)

Na metade do ano que vem eu pretendo arrumar um emprego de médico de Saúde da Família. No final do ano vou decidir se faço a prova de residência ou se trabalho mais um ano como médico de Saúde da Família para depois fazer a prova de residência. Pretendo fazer hoje em clínica médica e talvez depois em oncologia ou reumatologia. (A3)

A questão que se apresentou fortemente para o futuro, principalmente para os preceptores, foi a de como articular os necessários saberes e práticas integradores, que podem conformar identidades profissionais adequadas por meio de estímulos concertados, a um sistema de saúde que seja razoavelmente efetivo e estimulante para os profissionais.

As práticas que o PSF trabalha são realmente necessárias e há poucos como nós que conhecem e querem fazer. [...] mas me sinto muito desvalorizado pelas instituições, tanto universidade, como município [...] ganhar tão pouco e trabalhar tanto para fazer o que faço [...] se o consultório der certo, é possível que não fique. Em relação à idéia do 
PSF, acho que funciona, mas não representa um modelo [...] porque eu estou aqui com um cara com suspeita de abdome agudo, eu não tenho pra onde mandar o cara, não tenho referência. Consigo às vezes mandar, porque eu conheço, por exemplo, o pessoal da radiologia, mas é tudo eu, a minha pessoa. Se eu sair daqui, não funciona, então não é o sistema. O que mais se poderia fazer é capacitação de recursos humanos. Apesar de tudo, me sinto participando de um momento histórico, vamos dizer assim, é uma proposta de evolução e eu estou participando. (M1)

\section{CONSIDERAÇÕES FINAIS}

Os resultados da avaliação mostraram que havia se iniciado um exercício concreto de mudanças no âmbito do currículo do curso de Medicina. Um programa que articulava o ensino aos serviços de saúde e que fazia parte da sustentação desses processos - tendo em conta suas limitações, falhas e possibilidades - favoreceu o desenvolvimento de um movimento dinamizador. Este movimento se manifestou tanto na educação da saúde, facilitando o comprometimento com a emancipação das pessoas, como na mudança para um programa de saúde, o PSF, que correspondia às expectativas dos profissionais como modelo adequado às necessidades de saúde da população. Nesse sentido, a implantação do PSF no PDA como processo alternativo para a formação do profissional adequado começou a ocorrer nos dois campos, da educação e da prática, de forma relativamente simultânea, indicando possibilidades efetivas de mudanças.

O tipo de desempenho no presente e a socialização representada pela oferta da experiência pela universidade foram um fator explicativo potente para compreender a incorporação destas identidades por parte dos alunos e até mesmo para compreender novas variações na prática profissional, pois foi possível para estes médicos, ao longo da vida, exercer a medicina desenvolvendo práticas que se transformaram continuamente.

No futuro, estas práticas e saberes também poderão fazer parte da identidade profissional, da mesma forma que no presente as inovações modificaram e compuseram a identidade dos já médicos. Neste sentido, tutores que têm uma prática diária assistencial moldada no sistema público e no modelo PSF, e não apenas uma atuação docente, podem ter maior força estruturadora no processo de socialização do aluno.

As propostas políticas e programas são vivenciados pelos profissionais em diferentes locais, situações e momentos históricos. Portanto, há sempre uma reconstrução do perfil profissional, na medida em que existem diferentes concepções sobre a definição de suas práticas e variações sobre a expectativa de impacto de suas ações e interações. Observa-se, como no caso citado, que na implantação de um programa a expectativa é máxima, trazendo sempre um distanciamento entre o que é proposto e o que efetivamente acontece na execução.

Nessa perspectiva, a análise de uma intervenção sobre o mundo da cotidianidade dos serviços de saúde mostrou um processo em que foi possível deslocar o interesse da área dos problemas macro para os microssociais, onde os sujeitos concretos podem encontrar as possibilidades de construção de sua autonomia a partir da experimentação de novas relações sociais e de trabalho.

Este é o plano correspondente ao dos atores sociais, das acumulações sociais, onde as alterações nas relações técnicas atingem as relações sociais, possibilitando novas articulações e transformações entre os sujeitos sociais envolvidos.

Ao tomar este sentido, torna-se de suma importância destacar que as avaliações de experiências na área da educação médica e outras áreas da saúde não podem ter sua validade e êxito medidos sob critérios que levem em conta apenas aspectos técnicos e científicos, mas devem ser consideradas, sobretudo, do ponto de vista de sua validade ética e social.

\section{REFERÊNCIAS}

1. Ministério da Saúde. Saúde da Familia: uma estratégia para a reorientação do modelo assistencial Saúde. Brasília: Secretaria de Assistência à Saúde, Coordenação de Saúde Comunitária; 1997.

2. Ministério da Saúde. Avaliação da implantação e funcionamento do Programa de Saúde da Família no Brasil. Brasília: Secretaria de Assistência à Saúde; 2000.

3. Instituto Latinoamericano y del Caribe de Planificación Económica y Social. Centro Panamericano de Planificación de la Salud. Formulación de Políticas de Salud. Washington: OPS; 1975.

4. Fiszbeyn C. A Residência Médica como formadora de recursos humanos para o Sistema Único de Saúde no estado de São Paulo: uma visão crítica. São Paulo; 2000. Mestrado [Dissertação] - Universidade de São Paulo, Faculdade de Medicina, Departamento de Medicina Preventiva.

5. Marsiglia RG. Relação ensino-serviços: dez anos de integração docente-assistencial IDA no Brasil. São Paulo: Hucitec; 1995.

6. Vidal CA, Quiñones J. Integración docente-assistencial. Educación Médica y Salud. 1986;20(9):1-25

7. Rodriguez ML. Tendências de la Educación Medica en America Latina en los ultimos quince años: las professiones en México. Medicina. 1990;3. 
8. Chaves MM. Integração Docente-Assistencial: conceito e evolução histórica. Congresso Nacional da Rede Unida; 1993. 2; São Paulo. Salvador: UFBa; 1993. p.9-19.

9. Almeida MJ de. Educação Médica e saúde: lmites e possibilidades das propostas de mudança. São Paulo; 1997. Doutorado [Tese] - Universidade de São Paulo, Faculdade de Medicina, Departamento de Medicina Preventiva.

10. Malik AM. Qualidade em serviços de saúde nos setores público e privado. Cad. FUNDAP. 1996;(19):7-24.

11. Brasil. Constituição. Constituição da República Federativa do Brasil. Brasília: Senado; 1988.

12. Brasil. Lei Orgânica da Saúde n. 8080, de 19 de setembro de 1990. Dispõe sobre as condições para a promoção, proteção e recuperação da saúde, a organização e o funcionamento dos serviços correspondentes. Diário Oficial da União. Brasília, 20 set. 1990.

13. Dussault G. A gestão dos serviços públicos de saúde: características e exigências. Rev Adm Pública. 1992;26(20):819.

14. Dal Poz MR. Entre o prescrito e o realizado: estudo sobre a implementação do SUS no Estado do Rio de Janeiro e sua repercussão na política de recursos humanos em nível municipal. Rio de Janeiro; 1996. Doutorado [Tese] - Fundação Oswaldo Cruz, Escola Nacional de Saúde Pública.

15. Programa de incentivos a mudanças curriculares nos cursos de Medicina. Uma nova Escola Médica para um novo Sistema de Saúde. Brasília: M da Saúde, Secretaria de Políticas de Saúde. Ministério da Educação, Secretaria de Educação Superior; 2002.

16. Dubar C. Identidade profissional em tempos de bricolage. Contemporaneidade e Educação. 2001;6(9):152-56.

17. Hall S. Quem precisa de identidade? In: Silva TT. (Org.), Hall S, Woodward K. Identidade e diferença: a perspectiva dos estudos culturais. Petrópolis: Vozes; 2000.

18. Silva TT. A produção social da identidade e da diferença. In: Silva TT. (Org.), Hall S., Woodward K. Identidade e diferença: a perspectiva dos estudos culturais. Editora Vozes, Petrópolis, 2000.

19. Woodward K. Identidade e diferença: uma introdução teórica e conceitual. In: Silva TT. (Org.). Hall S, Woodward K. Identidade e diferença: a perspectiva dos estudos culturais. Petrópolis: Vozes; 2000.

20. Freidson E. Renascimento do profissionalismo: teoria, profecia e política. São Paulo: Ed. Universidade de São Paulo; 1998.

21. Freidson E. Profession of Medicine: a study of the Sociology of Applied Knowledge. Chicago:University of Chicago Press; 1988
22. Girardi SN. A situação atual dos Recursos Humanos em Saúde no Brasil (Sinais do mercado de trabalho e aspectos de sua regulamentação nos anos 90).Brasília: Ministério da Saúde, Coordenação Geral de Desenvolvimento de Recursos Humanos para o SUS; 1995. mimeo.

23. Wilson JQ. Bureaucracy: what government agencies do and why they do it. New York: Basic Books; 1989.

24. Rego S. O processo de socialização profissional na medicina. In: Machado MH. (Org.). Profissões da saúde: uma abordagem sociológica. Rio de Janeiro: Ed. Fiocruz; 1995.

25. Garcia JC. La educación medica en la America Latina. Washington: OPS; 1972.

26. Merton RK. Some preliminaries to a sociology of medical education appendix A socialization: a terminological note 287-293. In: Merton RK, Reader GG, Kenda PL (Ed.). The student-Physician Introductory Studies in the Sociology of Medical Education. Cambridge, Massachussets: Harvard University Press; 1957.

27. Souza AN. Formação médica, racionalidade e experiência. Ciênc saúde Colet. 2001;6(1):87-96.

28. Feuerwerker L, Sena R. La construcción de nuevos modelos acadêmicos de atención a la salud y de participación social. In: Almeida M, Feuerwerker L, Llanos C, Manoel (Org.). La educación de los preofessionales de la salud en Latino America: teoria y práctica de un movimiento de cambio. São Paulo: Hucitec; 1999. Tomo 1.

29. Davini MC. Educación permanente y problematización de la practica: caminos metodológicos. In: Haddad J, Roschke MA, Davini MC. Educación permanente de personal de salud. Washington: OPS; 1994. p. 109-12. (série desarrollo de Recursos Humanos, 100).

30. Sisson MC. Avaliação da implantação do Programa de Saúde da Família no Programa Docente-Assistencial de Florianópolis. São Paulo; 2002. Doutorado [Tese] -, Universidade de São Paulo, Faculdade de Medicina.

31. Greene JC. Qualiative Program evaluation. In: Denzin NK, Lincoln YS. Handbook of qualitative research. Thousend Oaks: Sage Publications; 1994.

32. Miles MB, Huberman AM. Qualitative data analysis: an expanded sourcebook. $2^{\text {nd }} \mathrm{ed}$. Thousend Oaks: Sage publications; 1994.

33. Becker HS. Métodos de pesquisa em ciências Sociais. São Paulo: Hucitec; 1994.

34. Minayo MCS. O desafio do conhecimento: pesquisa qualitativa em saúde. São Paulo: Hucitec; 1992

35. Triviños ANS. Introdução à pesquisa em Ciências Sociais: a pesquisa qualitativa em educação. São Paulo: Atlas; 1995. 
36. YIN RR. Case study research: design and methods. $2^{\text {nd }}$ ed. Thousand Oaks: Sage Publication; 1994. Applied Social Research Methods Series, v. 5.

37. Patton MQ. Qualitative evaluation and research methods. $2^{\text {nd }}$ ed. Newsbury Park, CA: Sage Publication; 1990.

38. Programa Docente Assistencial. Projeto. Universidade Federal de Santa Catarina, Secretaria Municipal da Saúde de Florianópolis; 1997 abr. Mimeo.
CONFLITOS DE INTERESSE

Declarou não haver

\section{ENDEREÇO PARA CORRESPONDÊNCIA}

Maristela Chitto Sisson

Travessa Erotides Maria Oliveira, 116

Lagoa da Conceição

CEP. 88062-170 - Florianópolis - SC

E-mail: mcs@mbox1.ufsc.br 